\title{
Hesitant Language Use and Self-Esteem in Adolescent Girls Across Ethnicity
}

\author{
Lucy Sopher ${ }^{1 *}$ and Angelica Puzio#
}

${ }^{1 *}$ Riverdale Country School, Bronx, NY, USA

${ }^{2 \# N e w ~ Y o r k ~ U n i v e r s i t y, ~ N e w ~ Y o r k, ~ N Y, ~ U S A ~}$

"Sole Author, "Mentor

\section{ABSTRACT}

Language is dynamic and changes across the course of adolescence. Researchers have found that usage of some words and phrases, such as "um..." and "I don't know," increase during the teenage years, especially when youth are confronted with topics that they may not feel comfortable discussing. Hesitant language is defined as words or styles of speech that communicate 1 . a distancing of the declarative content of one's speech and 2. interpersonal sensitivity towards the listener. These phrases are typically used because one is nervous or unsure about what to say and they can signify a variety of issues and may or may not be linked to self-esteem. In this study, I analyzed eighth grade girls' usage of hesitant language and how the use of this type of language may or may not be correlated with their scores on the Rosenberg self-esteem test. I also ran an ANOVA to determine if there was a significant difference in correlation across ethnicity. The results suggest that significant, quantifiable differences exist between participants of different ethnicities in the relationship between hesitant language usage and self-esteem. There have been very few studies done on how hesitant language and self-esteem correlate and change through girls' adolescence. I hope this study will help add to the important conversation around girls' self-esteem and what can be used as indicators of a change in that selfesteem over time.

\section{Introduction}

The use of language throughout adolescence is highly dynamic and poses an opportunity to predict other changes in mental health and well-being, such as self-esteem. Previous research has demonstrated an increase in usage of some words and phrases, such as "um..." and "I don't know," during the teenage years, especially when youth are confronted with topics that they may not feel comfortable discussing. One of the few studies done on hesitant language looked at adolescent girls' use of the words "I don't know" when discussing sexual health topics (Short, Mills, \& Rosenthal, 2006). The words "I don't know" were found to serve one of three purposes: used as a placeholder, much like someone would say "um," used to not answer a question, or used to reduce a girl's commitment to her opinion. In adolescence, the use of hesitant language, especially because one is nervous or unsure about what to say, can signify a variety of issues and may or may not carry underlying meaning. Such words and styles can communicate a distancing of the declarative content of one's speech or an interpersonal sensitivity toward the listener, and is thus defined as hesitant language.

There is a body of research that has documented what adolescent girls say and how that differs from what adolescent boys say (Sheldon, 1992; Blair, 2000; Cribb \& Haase, 2015). Eckert (1988) studied the adolescent speech patterns through the lens of gender and found that young women were more likely to have more affected speech and show more differences in their phonological sounds. The researcher hypothesized that this difference may be because girls had to use symbolic means to assert their roles rather than physical force or social mobility. Most literature documenting changes in girls' self-esteem through their teenage years into adulthood (Gilligan, Rogers, \& Noel, 2018; Strange, Neuenschwander, \& Dauer, 2005) has reinforced the American Association of University Women survey 
that showed a steep decline in confidence as girls reach adolescence (Orenstein, 1994). Gilligan, Rogers, and Noel (2018) noted that when researchers asked one of the girls how it felt to be a part of the research project the girl replied, "It's just odd, peculiar, strange. I don't know...Hmm, I don't know." This use of hesitant language was then questioned by the researchers, for whose benefit was the girl using this language?

Overall there is a small and diverse body of literature on hesitant language and a subset of those papers looks specifically at self-esteem. In this study, I analyzed eighth grade girls' usage of hesitant language and how the use of this type of language may or may not be correlated with their scores on the Rosenberg self-esteem test and their selfreported ethnicity.

\section{Methods}

The study aimed to understand how hesitant language relates to self-esteem across ethnic groups in adolescent girls. I investigated whether the analysis of hesitant language use could be used as a marker for self-esteem in the research subjects. Specifically, the research question asks whether there is a correlation between hesitant language use and selfesteem, and whether this differs significantly across ethnicity. I hypothesized that since hesitant language use can often indicate distancing of declarative content across speech, it could also serve as a metric to assess self-esteem in 8 th grade girls.

This project looked for correlations between the two by analyzing data drawn from a larger mixed-method, longitudinal study examining children and adolescents' social, emotional, and academic development. In that study, semi-structured interviews were conducted with 102 adolescent girls over a five-year period beginning in 2007. Participants were 24.5\% African-American, 24.5\% Chinese American, 25.5\% Hispanic or Latina, and 23.5\% White. The study used Rosenberg's 1965 Self Esteem Scale to collect data about self-esteem and focused on self-identified female students' answers, to track their self-esteem and compare self-esteem averages across grades. The girls were interviewed three times, in 6th, 8th, and 11 th grades, by trained interviewers, and protocol topics included questions about daily routines, school and home life, friendships, social identities, and future aspirations. For the purposes of the project, the interviews were transcribed and coded, and researchers counted the frequency of hesitant language. Hesitant language was coded as the frequency of four phrases identified by past researchers: "I guess," "I mean," "like," and "I don't know." I analyzed this data for correlations between hesitant language use and self-esteem and conducted four ANOVA tests with Tukey's Honestly Significant Difference (HSD) to determine whether the usage of hesitant phrases by female students differs by self-reported ethnicity.

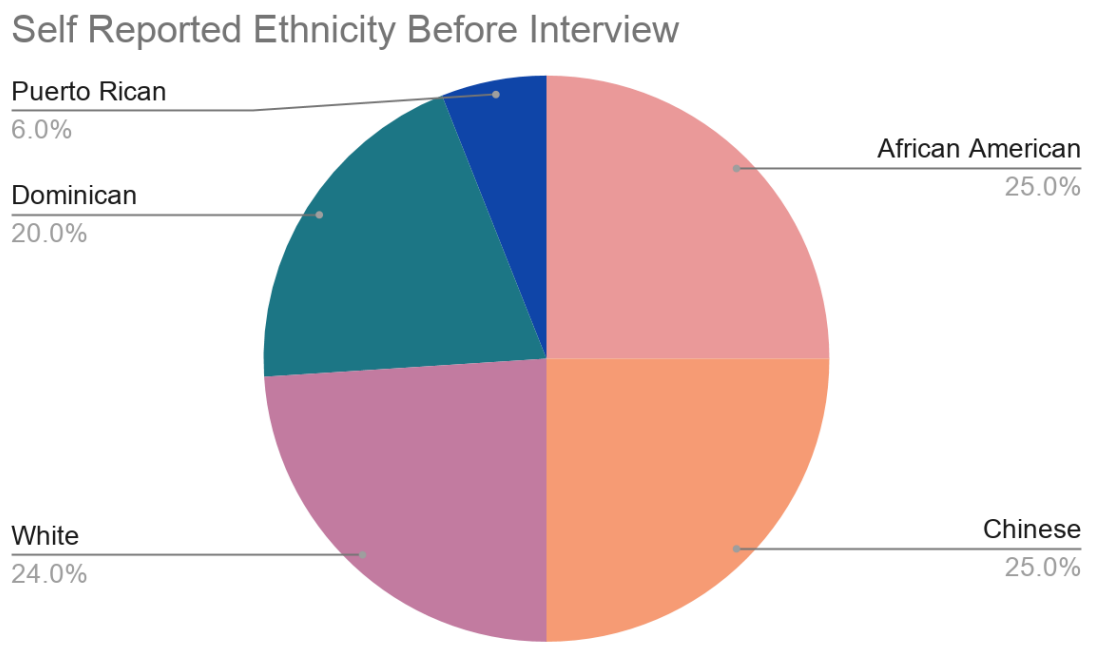

Figure 1. Self-reported ethnicity of adolescent girls interviewed in the study. 


\section{Results}

The study aimed to determine whether the usage of hesitant phrases differs by ethnic group or correlates with selfesteem, calculating statistical significance with ANOVA and Tukey's Honestly Significant Difference (HSD) test. Mean and standard deviation varied for each hesitant language phrase; "like" had the highest mean $(M=735.30, S D=$ $21.48)$, but "I don't know" varied the most substantively $(M=47.38, S D=39.50)$.

\section{Mean and Standard Deviation of Hesitant Language Usage}

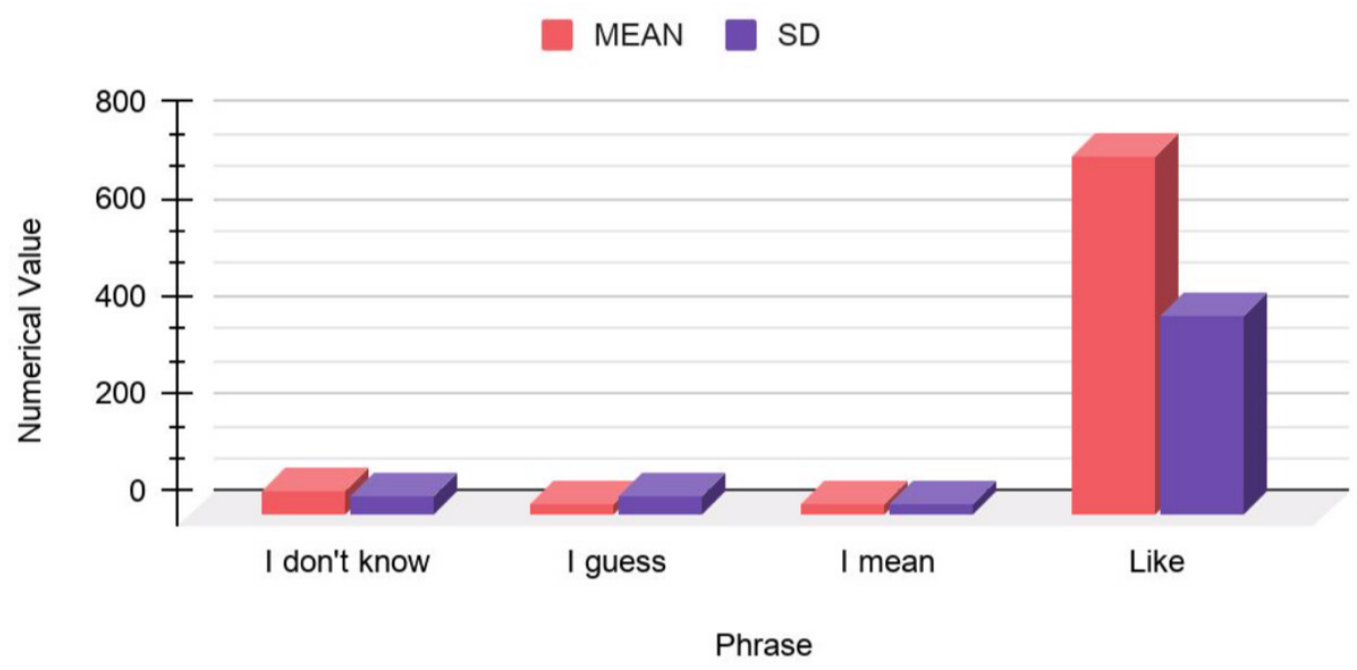

Figure 2. Mean and standard deviation (SD) for four phrases coded as hesitant language in the interviews with adolescent girls.

The results did not find significant correlations between self-esteem and hesitant language usage across all 8th grade girls. Interestingly however, the data showed several correlations between hesitant language use and self-esteem across ethnicity. For White participants, "I mean" and "like" were moderately correlated with self-esteem $(r=0.27 ; r=0.23)$. Chinese participants and White girls showed the same correlation between "like" and self-esteem $(r=0.23)$; Chinese participants also showed moderate correlation between the use of "I guess" and self-esteem $(r=0.41)$. For Dominican and Puerto Rican girls, usage of "I guess" was somewhat correlated negatively with self-esteem $(r=-0.24)$.

Table 1. Correlations between usage of hesitant language phrase and self-esteem by self-reported ethnicity. AA: African American; DR/PR: Dominican and Puerto Rican.

\begin{tabular}{|c|c|c|c|c|}
\hline \multirow{2}{*}{ Hesitant Language Phrase } & \multicolumn{4}{|c|}{ Self-reported Ethnicity } \\
\cline { 2 - 5 } & Chinese & AA & DR/PR & White \\
\hline I guess & 0.41 & 0.06 & -0.24 & 0.13 \\
\hline Like & 0.23 & 0.30 & 0.03 & 0.19 \\
\hline I don't know & 0.23 & 0.15 & -0.04 & -0.10 \\
\hline I mean & -0.05 & -0.11 & -0.08 & 0.27 \\
\hline
\end{tabular}

The results also showed significant differences between frequency of specific hesitant language phrases and ethnicity, as shown in Table 2. 
Table 2. Significant results from ANOVA comparing hesitant language usage by ethnicity. AA: African American.

\begin{tabular}{|c|c|c|c|}
\hline Hesitant Language Phrase & Significance & $\begin{array}{c}\mathrm{F}(\mathrm{df} \text { between } \\
\text { groups, df } \\
\text { within groups })\end{array}$ & $\mathrm{p}$-value \\
\hline I guess & $\begin{array}{c}\text { White girls } \\
\text { more likely to } \\
\text { use phrase than } \\
\text { AA or Chinese } \\
\text { girls }\end{array}$ & $\mathrm{F}(4,67)=4.35$ & $\mathrm{p}=0.003$ \\
\hline I mean & $\begin{array}{c}\text { White girls } \\
\text { more likely to } \\
\text { use the phrase } \\
\text { than all other } \\
\text { ethnic groups }\end{array}$ & $\mathrm{F}(4,67)=6.998$ & $\mathrm{p}<0.001$ \\
\hline
\end{tabular}

\section{Discussion}

My study investigated the interaction between self-esteem and hesitant language in female adolescents of different ethnic groups. This study aimed to add another dimension to the broadening topic of hesitant language by looking not only at self-esteem but also how hesitant language usage my have some relationship with ethnicity. While I did not find a significant correlation between self-esteem and hesitant language usage, the results suggest that significant, quantifiable differences exist between participants of different ethnicities in the relationship between hesitant language usage and self-esteem. That is, specific phrases were significantly correlated to self-esteem for girls of a certain ethnicity; for example, the frequency of "I guess" usage was correlated with higher self-esteem among Chinese participants.

Self-esteem is an important construct in psychological research, and has been previously established as an important diagnostic feature of a wide range of anxiety-related disorders. This study adds to the body of research about self-esteem and these data indicate that hesitant language usage could be a powerful predictive tool when evaluating self-esteem in psychotherapeutic practice for adolescents. More work is needed in this field to better understand the complex significance of specific hesitant language in different ethnicities.

In this study trained researchers ensured the phrase counts accurately reflected participants' intentions did context-based coding of hesitant language. While I defined hesitant language as communicating a distancing from declarative content or expressing interpersonal sensitivity toward the listener, a more nuanced understanding of which phrases fit this definition is required to fully understand the frequency of hesitant language usage in the participants' interviews and this can only occur through more data collection and analysis. It is the researcher's hope that through this study the understanding in the field around hesitant language will be furthered and the use of the term hesitant language will be more widely recognized.

The study also investigated whether significant differences exist between people of different ethnicities in the relationship between hesitant language usage and self-esteem, something that has not been widely researched. The study used a relatively small sample size, with only about 25 students per ethnic group, limiting the generalizability of the findings. Since the data for the analysis was drawn from a larger, mixed-method longitudinal study, some of these factors are outside the study's control.

Despite limitations, this study design and data had many strengths that warrant further investigation into this subject. This study builds on previous research exploring self-esteem in female adolescents, including Strange, Neuenschwander, and Dauer (2005). This work showed no significant differences in self-esteem across age groups, an unexpected finding that could be attributed to the limitations of the Rosenberg's Self Esteem Scale. 
This study used Rosenberg's 1965 Self-Esteem Test and Scale, a validated self-report measure for self-esteem. Even so, some researchers have raised the possibility of bias introduced by the phrasing of positive and negative items in the test. The possibility of self-reporting bias also exists since adolescents may have more unstable self-esteem than older individuals, and research has indicated that they tend to view themselves more negatively. Even though widely used, the RSE test could have limited the study's ability to fully understand the relationship between hesitant language usage and self-esteem in female adolescents.

In future work, to better correct for biases introduced in the self-reported RSE, I hope to reanalyze the data using the Children's Depression Inventory (CDI). The CDI might better evaluate the relationship between hesitant language usage and the emotional well-being of adolescents. It is the researcher's belief that this research and followup studies can eventually allow clinicians to offer more effective and personalized care to adolescents. It is my hope that if the predictive nature of hesitant language usage is realized, it can provide an additional metric to improve the quality and sensitivity of psychotherapy.

\section{Acknowledgements}

I would like to thank the mentors who have helped me get to this point in my research journey, Angelica Puzio, Niobe Way, Rachel Cox, and Kelley Nicholson-Flynn.

\section{References}

Blair, H.A. (2000). Genderlects: girl talk and boy talk in a middle-years classroom. Language Arts, 77(4), 315-323.

Cribb, V.L. \& Haase, A.M. (2016). Girls feeling good at school: School gender environment, internalization and awareness of socio-cultural attitudes associations with self-esteem in adolescent girls. Journal of Adolescence. 46, 107-114. https://doi.org/10.1016/j.adolescence.2015.10.019

Downey, Maureen. (2012). Girls and middle school: drama and divas. The Atlanta Journal - Constitution, A10.

Eckert, P. (1988). Adolescent social structure and the spread of linguistic change. Language in Society, 17(2), 183207. https://doi.org/10.1017/S0047404500012756

Gilligan, C., Rogers, A.G., \& Noel, N. (2018). Cartography of lost time: mapping the crisis of connection. The Crisis of Connection: Roots, Consequences, and Solutions. ed. Niobe Way. New York University Press, New York.

Moran, P. \& Eckenrode, J. (1991). Gender differences in the costs and benefits of peer relationships during adolescence. Journal of Adolescent Research, 6(4), 369-409. https://doi.org/10.1177/074355489164002

Onetti, W., Fernandez-Garcia, J., Castillo-Rodriguez, A. (2019). Transition to middle school: self-concept changes. Plos One, 14 (2). https://doi.org/10.1371/journal.pone.0212640

Orenstein, P. (1994). School girls: Young women, self esteem, and the confidence gap. New York: Doubleday Dell Publishing Group.

Pipher, M. (1994). Reviving Ophelia: Saving the selves of adolescent girls. New York: Ballantine Books. 
Polce-Lynch, M., Myers, B.J., Kliewer, W., \& Kilmartin, C. (2001). Adolescent self-esteem and gender: exploring relations to sexual harassment, body image, media influence, and emotional expression. Journal of Youth and Adolescence, 30(2), 225-244. https://doi.org/10.1023/A:1010397809136

Richman, C., Clark, M.L., Brown, K.(1985). General and specific Self-esteem in late adolescent students: race x gender x SES effects. Adolescence, 20, (79).

Sheldon, A. (1992). Conflict talk: Sociolinguistic challenges to self-assertion and how young girls meet them. Merrill-Palmer Quarterly, 38(1), 95-117.

Short, M.B., Mills, L.C., \& Rosenthal, S.L. (2006). When adolescent girls say, “I don't know.” Pediatrics, Adolescence, and Gynecology. 19, 267-270. https://doi.org/10.1016/j.jpag.2006.05.001

Strange, J.L., Neuenschwander, N.L., \& Dauer, A.L. (2005). Self-esteem in females throughout childhood and adolescence. Undergraduate Research Journal for the Human Sciences, 4. 